tionally credited with a uterine action, some because of interest aroused by pharmacological research. It would be pointless at this time to attempt any complete list. One drug, however, is now arousing interest and deserves special mention. This is a purified lupanine base to which the name sparteine has been given.

Sparteine, a naturally occurring alkaloid, has been known to pharmacologists for many years. So long ago as 1873 it was employed as a corrective for certain cardiac irregularities. Because of a supposed analogy between the heart muscle and uterine muscle, and also because of certain pharmacological observations reported by Tamba in 1921, it was occasionally employed in the hope that it would induce the onset of labour or speed the progress of labour already started. With the introduction of standardized and of synthetic preparations a new interest has been stimulated, and there is now a considerable literature relating to this drug, more especially in the American journals.

In this country sparteine has been given a trial in several centres. Embrey and Yates (1964), in Oxford, have shown by tocograph tracings in the human subject that it has an undoubted oxytocic effect which in quality resembles that of oxytocin although with an action somewhat less consistent.

\section{A Backward Look}

The olinical trial of sparteine continues, but meantime it would be prudent to bear in mind the history of other uterine stimulants. First there was astonishment on discovering the effect. Next there was a cautious employment of the drug in labour. Then came the period of uncritical and reckless use. Lastly, there was the sober realization that a substance beneficial in reasonable dosage, or in the presence of weak uterine contractions, becomes a danger when administered in high dosage or when the uterus is already briskly active.

Here let me recall the words of the late Joseph B. DeLee, long the doyen of American obstetrics. He was referring to the misuse of pituitary extract, but equally well his warning might be applied to all oxytocic agents. "A streamlined labour," he said, "is as safe as a streamlined parachute."

And now to add a grim note. Already cases of uterine tetany and of uterine rupture are reported following the use of sparteine. The wheel completes its circle.

I started this lecture by referring to the mortality from post-partum haemorrhage. Many of our present-day students have never witnessed the sudden torrential bleeding so dreaded by our obstetric forebears ; far less have they heard of any death from this cause. This, then, is the token of the debt we owe to the pharmacological laboratories of many countries where patient co-ordinated research-often wearisome, often unspectacular, often without hint of practical applicationmay in the end yield a reward which, reckoned in the saving of human life, places it among the enduring achievements of medical science.

\section{BIBLIOGRAPHY}

Barger, G. (1931). Ergot and Ergotism. Edinburgh

Douglas, R. G., Bonsnes, R. W., and Du Vigneaud, V. (1955). Obstet. and Gynec., 6, 254.

Du Vigneaud, V., Ressler, C., Swan, J. M., Roberts, C. W., and Katsoyannis, P. G. (1954).' F. Amer. chem. Soc., 76, 3115.

Dudley, H. W., and Moir, J. C. (1935). Brit. med. F., 1, 520.

Embrey, M. P., Barber, D. T. C., and Scudamore, J. H. (1963). Brit. med. f., 1, 1387.

- and Yates, M. J. (1964). F. Obstet. Gynaec. Brit. Cwlth, 71, 33.

Moir, J. C. (1932). Brit. med. F., 1, 1119. (1944). 7. Obstet. Gynaec. Brit. Emp., 51, 181.

(1955). Canad. med. Ass. F., 72, 727.

Nixon, W. C. W., and Smyth, C. N. (1957). 7. Obstet. Gynaec. Brit. Emp., 64, 35

Robso:z. J. M. (1933). F. Physiol. (Lond.), 78, 309 ; 79. 83.

\title{
The Benign Form of Multiple Sclerosis: Results of a Long-term Study
}

\author{
DOUGLAS MCALPINE,* M.D., F.R.C.P.
}

Brit. med. F., 1964, 2, 1029-1032

- “. . . enfin il n'est pas rare de voir des intermissions complètes qui ont pu faire espérer une guérison définitive." Charcot, 1872.

In a disease so variable in its course as multiple sclerosis, prognosis in an early case will remain beyond the grasp of the physician unless an effective form of treatment is forthcoming. In the meantime some light can be thrown on this problem by studies which, although not truly prospective, follow uniform methods of diagnosis and evaluation of disability over a span of years. One such study was completed in 1959 (McAlpine, 1961). It was confined to 241 patients in whom the disease had begun between January 1930 and December 1949 and who had been seen at the Middlesex Hospital within three years of onset. In all but one case the diagnosis had been " multiple (or disseminated) sclerosis," qualified sometimes by the adjective " probable," " possible," or " suspect."

Of these 241 patients, 83 (34\%) had died, 80 (33\%) were disabled in varying degree, and $78(32 \%)$ were "unrestricted"

* From the Institute of Clinical Research, the Middlesex Hospital Medical School, London. -that is, "without restriction of activity for normal employment and domestic purposes but not necessarily symptom-free" (McAlpine and Compston, 1952). All the patients in this group were working either away from or at home and could walk at least half a mile $(0.8 \mathrm{~km}$.) without a rest or support from a stick.

\section{Present Study}

A further five-year follow-up of these 78 patients has been completed. In the autumn of 196257 were examined and information about all but one of the remainder was obtained by letter. During March-May 196463 patients attended for examination, letters were received from general practitioners in nine instances, while five patients (one living in West Africa and another in U.S.A.) replied to questions regarding their health (Table I).

The three patients who died were in category " unrestricted." Two were classified as possible cases.

A single woman aged 28 noticed "pins and needles" and slight weakness of the right hand on 11 September 1937. About 15 
TABLE I.-Results of 1964 Follow-up of 78 Cases of Multiple Sclerosis in Category "Unrestricted" in 1959

\begin{tabular}{|c|c|c|c|c|}
\hline Dead & Disabled & Unrestricted & Untraced & Total \\
\hline M 1. F 2 & M 3. F 9 & M 22. F 40 & 1 & 78 \\
\hline
\end{tabular}

October the left leg felt numb and stiff. On 29 October symptoms had nearly cleared; no definite organic signs were evident on examination. During the war she served in India as an officer in the W.A.A.F. and remained well except for a mild relapse in 1942. From 1946 onwards she worked in Portugal. In March 1960 she wrote: "To sum up. I have over the years been conscious from time to time of a slight weakness in the left leg, but have led a perfectly normal active life and have been quite fit." On 13 May 1961 she died within 24 hours from " heart failure and pulmonary oedema."

A married woman, first seen in 1943 at the age of 23 in the second year of the disease, had 17 relapses, mainly sensory, in the course of the next 18 years. Pyramidal signs, however, remained minimal. Subject to attacks of depression which led to admission to a mental hospital on two occasions, she finally gassed herself in O'ctober 1961 at the age of 41 .

The third patient, a man aged 64, died from carcinoma of the lung in May 1964 in the twenty-fifth year of the disease.

The three patients who died and one untraced have been omitted from Table II and subsequent tables and calculations.

In 12 patients the disease began between the ages of 15 and 19 and in 33 in their fourth decade, thus accounting, in part, for the fact that 39 patients are now aged 50 or over.

TABLE II.-Age Distribution of 74 Multiple-sclerosis Patients Followed Until the Fifteenth Year or More of the Disease

\begin{tabular}{c|c|c|c|c|c|c}
\hline $\begin{array}{c}\text { Age in } \\
\text { Years: }\end{array}$ & $30-39$ & $40-49$ & $50-59$ & $60-69$ & $70+$ & Total \\
\hline Males.. & 5 & 7 & 8 & 4 & 0 & 24 \\
Pemales. & 10 & 13 & 20 & 6 & 1 & 50 \\
\hline Total. & 15 & 20 & 28 & 10 & 1 & 74 \\
\hline
\end{tabular}

The weighted mean duration of the disease is 18.2 years, with a range of 15-34 years.

Twelve patients are now disabled, six somewhat severely. In nine progression of the disease was mainly or wholly responsible for the deterioration, although in two patients an hysterical overlay played a part. In three patients disability was mainly or entirely due to some associated condition-arthritis in two women, aged 62 and 63, and heart failure in another, aged 63. Of the 12 disabled patients five are in the fifth, four in the sixth, and one in the fourth decade of life. Those multiplesclerosis patients who survive into the 60- and 70-year agegroups will not escape the risk of the usual disabilities of the elderly.

\section{Diagnostic Criteria}

The following definitions cover all patients in the present survey (McAlpine, 1961).

Definite.-A history of an acute retrobulbar neuritis or of an episode of paraesthesiae, motor weakness, double vision, unsteadiness in walking, or other symptom known to occur in multiple sclerosis which tended to improve or clear up, followed by one or more relapses during the course of years with, in addition, the presence of pyramidal and other signs indicative of multiple lesions in the central nervous system when the patient was first seen or subsequently. In mild cases these signs may remain minimal for many years.

Probable.-(1) During the original attack clinical evidence of multiple lesions which at the time suggested the probability or possibility of multiple sclerosis, followed by a good recovery. During a lengthy follow-up relative or complete absence of fresh symptoms after the first year, but with a tendency to variability in pyramidal and other signs originally present or the occasional late appearance of an extensor plantar response, nystagmus, tremor, or temporal pallor of a disk. (2) A history of one or more attacks of acute retrobulbar neuritis accompanied or followed by pyramidal signs, usually mild in degree. Subsequently no clinical evidence of relapse.

Possible.-A history similar to that described under " probable but with unusual features or paucity of signs.

The relative proportion of patients in each category was: definite 48 ; probable 16 ; possible 10.

\section{Symptoms and Signs}

Initial Symptoms.-The significant findings were: (1) a high incidence of paraesthesiae in $38(50 \%)$ patients-in 16, sensory symptoms were accompanied by motor weakness; (2) acute retrobulbar neuritis in $27(36 \%)$ patients-in 20, or roughly one in four, as the sole presenting symptom ; (3) motor weakness, usually slight in degree, was noted by one patient in every three, but in only two patients did it occur alone. The corresponding percentages in a recent study of 144 unselected cases at the Mayo Clinic were: (1) paraesthesiae 42, (2) retrobulbar neuritis 28, (3) "gait difficulties (in one or both legs)" 21 (Ivers and Goldstein, 1963).

Pyramidal Signs.-Disability in multiple sclerosis depends almost entirely on the extent to which pyramidal and cerebellar pathways become affected. Table III compares initial findings with those observed in 1964.

TABLE III.-Comparison of Early and Late Pyramidal Signs in 74 Cases of Multiple Sclerosis Followed Until the Fifteenth Year or More of the Disease

\begin{tabular}{lll|r|r|r|r|r|r}
\hline Pyramidal Signs*.. &. &. & 0 & 1 & 2 & 3 & 4 & Unknown \\
\hline $\begin{array}{lll}\text { Within 3 years of onset } \\
\text { Spring 1964 }\end{array}$ & $\ldots$ & 26 & 20 & 11 & 16 & 1 & 0 \\
\end{tabular}

* Key to pyramidal signs: $0=$ Reflexes normal apart from unilateral exaggeration in some cases. $1=$ Deep reflexes exaggerated, in some cases unequally, with
unilateral or bilateral equivocal plantar response. $2=$ Unilateral extensor response. unilateral or bilateral equivocal plantar response. 2 = Unilateral extensor response.
3 = Early bilateral extensor plantar response with mild paresis or normal power. $3=$ Early bilateral extensor plantar response with mild paresis or normal power.
$4=$ Well marked extensor responses with moderate or severe degree of paraplegia.

When first examined 28 of the 74 patients showed an extensor plantar response on one or both sides, but with one exception the degree of paresis was slight. In the remaining 46 patients pyramidal signs were either absent (26) or were minimal in degree (20). As expected there is a sharp fall in the number of patients. who are still without detectable pyramidal signs, while the number with well-marked signs has increased from one to six ; the last figure includes those who are now much disabled. Eleven of the 16 patients with a unilateral extensor plantar response are at present in category unrestricted while five are restricted-that is, able to walk unaided for short distances (up to half a mile) and able to get on and off public transport. Three of these patients have an associated cause for disability as mentioned earlier. In the benign form of multiple sclerosis early bilateral plantar responses may be found after some years in patients who show little or no impairment of power in the lower limbs. This finding was present in 15 out of 62 patients who are still in category unrestricted.

Cerebellar Signs.-At the initial examination only $10(13 \%)$ of the 74 patients showed some degree of cerebellar disturbance, contrasting with the figure of $41 \%$ in those patients in the original series who subsequently died or became disabled. In 1964, eerebellar signs were evident in 19 out of 63 patients who were examined-mild intention tremor in nine, more pronounced in two, both considerably disabled. Unsteadiness in walking or in turning was observed in eight patients, four of whom were in category restricted.

Acute and Subacute Brain-Stem Signs.-These were conspicuous at onset in 16 patients. The clinical picture is illustrated by the following case reports:

A medical practitioner aged 35 was admitted to hospital in East Africa on 17 December 1948 with a 24-hour history of stupor. 
The history was negative apart from paroxysmal rhinitis for the past year and chronic loa-loa. Dr. J. B. Jelliffe noted dysarthric speech, nystagmus, a right-sided intention tremor, and ataxia when the patient attempted to walk. C.S.F.: lymphocytes $60 /$ c.mm., protein $40 \mathrm{mg} . / 100 \mathrm{ml}$. On admission to the Middlesex Hospital on 21 December he was mentally alert but had partial amnesia for the first two days of his illness. Apart from mild dysarthria and nystagmus (horizontal and vertical) no abnormal signs were present. C.S.F.: cells $6 / \mathrm{c} . \mathrm{mm}$., protein $40 \mathrm{mg} . / 100 \mathrm{ml}$. W.R. negative ; Lange curve 12333 . This last finding, the rapid recovery, and the absence of headache and fever initially raised the possibility of multiple sclerosis. In the early spring of 1949 he returned to work in West Africa. On 7 April 1955, while on leave in Scotland, he relapsed with sensory symptoms suggesting a spinal-cord lesion. On 4 June Dr. John Marshall noted slight weakness of the left leg and increased deep reflexes on this side, but both plantar responses were flexor. Since 1955 there has been no further relapse. Slight weakness and stiffness of the left leg have persisted, which up till March 1964, however, had not prevented his carrying out full medical duties as well as a "regular 18 holes of golf."

A girl aged 19, while on the waiting-list for tonsillectomy, was admitted to hospital in August 1930 with a history of headache and backache for the previous six months and more recently a tendency to stumble. For two weeks she had double vision and had had difficulty in seeing with the right eye. For one week speech had become slurred, and weakness with unsteadiness of the legs had rapidly progressed. Examination proved difficult on account of involuntary laughter and crying. Speech was unintelligible. A right-sided papillitis with central scotoma, a right external rectus palsy, lateral nystagmus, gross ataxia in all limbs, and bilateral pyramidal signs were the main findings. She was unable to stand unsupported. C.S.F. was completely normal. She progressively improved, and when discharged on 15 October could walk unaided. Ataxia was minimal and plantar responses equivocal. Tonsillectomy was performed on 27 April 1931. She was readmitted on 14 April 1933 with a return of brain-stem signs similar to those previously noted except that plantar responses were flexor. Since 1933 she has worked full-time as a civil servant, having had only three mild relapses, the last being in 1953. Euphoria and nystagmus have persisted since the onset. Early extensor plantar responses were noted in 1950 and on two subsequent occasions; in March 1964 only a unilateral response was obtained. The gait appeared normal.

These two cases typify the occasional explosive nature of brain-stem multiple sclerosis. They further illustrate the excellent recovery which may be observed in such cases.

Other Signs.-Of the 63 patients personally examined in 1964, pallor of the optic disk (unilateral or bilateral) was found in 46 , nystagmus in 20 , and euphoria in 10 .

\section{Relapses}

A previous analysis of the average number of relapses each year in 78 patients in category unrestricted in 1959 showed that 23 had no significant relapse after the first year. Excluding these patients, the average number of relapses in the remaining 55 patients was highest in the first two years $(0.7$ and 0.6 respectively). In the next eight years the number per year fell to 0.2 and after the tenth year there was a further decline.

Up till the spring of 1964, 14 of the 23 patients mentioned above had not so far relapsed, but old or new signs appeared at varying intervals in some patients. Although these cases are distinctly uncommon (about 6 in every 100), their importance in broadening our clinical and histological concept of the disease and in judging the results of therapeutic trials must be emphasized.

A man aged 47 was admitted to hospital on 24 June 1948 with a history of double vision for two weeks. Positive findings were: paresis of left internal rectus, horizontal and vertical nystagmus, and exaggerated deep reflexes on the right side. C.S.F.: W.R. negative; Lange curve 02333. Lateral nystagmus and reflex changes persisted. In 1951 the right plantar response became extensor and has remained so. In the spring of 1964 he was still working full-time as a tailor. Signs were unchanged.
A youth aged 18 was seen on 4 December 1947 with a history of an acute retrobulbar neuritis (R) dating from 16 August. Marked pallor of the optic disk and exaggerated deep reflexes on the left side were noted. These signs remained unaltered until October 1959, when generalized hyperreflexia and equivocal plantar responses were evident. In March 1964 he reported that he was well, apart from a tendency to tire somewhat easily. In addition to the signs noted in 1959 the jaw-jerk was notably increased for the first time.

The following were classified as possible cases.

While serving in the R.A.F., a youth aged 19 was admitted to Hospital at Halton Camp in September 1941 on account of a rapid onset of numbness and weakness in the limbs, retention of urine, and double vision. His temperature was normal and he did not complain of headache. There was no history of recent vaccination or of an infectious fever. C.S.F.: cells $2 /$ c.mm., protein $60 \mathrm{mg} . / 100 \mathrm{ml}$., Lange curve 11344 . A diagnosis of "acute disseminated sclerosis" was made by Wing-Commander R. Ironside. The patient made an excellent recovery but was invalided out of the Service. In 1949, 1959, 1962, and 1964 he reported to us that he had remained well. On each occasion examination was negative apart from exaggerated deep reflexes in the left limbs.

In November 1942 a girl aged 19 had an attack of blurred vision in the left eye attributed to retrobulbar neuritis. Three months later, when admitted to the Middlesex Hospital for tonsillectomy, a neurological examination by Dr. P. H. Sandifer showed left pyramidal signs, including an extensor plantar response. Subsequently she married and moved to the U.S.A. Between 1957 and 1964 she has reported by letter every two years. Despite having borne 11 children, all of whom are alive, she has not relapsed. In 1962, at my request, she consulted a neurologist; he could find no evidence of organic nervous disease. In April 1964 she wrote that apart from the discomfort of varicose veins she remained well.

In these 14 cases initial symptoms varied: retrobulbar neuritis in 3 ; double vision in 3 ; acute brain-stem in 4 ; spinal cord in 2 ; acute brain-stem and spinal cord in 2 .

\section{Discussion}

The possibility of recovery from multiple sclerosis visualized by Charcot (1872) has since then occurred to few (Marie, 1895 ; Bramwell, 1917 ; Birley and Dudgeon, 1921). Nearly 30 years ago, in words of singular perception, Brain (1936) summarized his views on prognosis: "If a remission may last thirty years why not for a lifetime? The overwhelming number of patients in whom the disease is progressive should not blind us to the probability that the continuous series from the most acute to the most benign forms extends further to include those in whom a first attack is never followed by another."

Laborious though the follow-up method may be, it remains the sole means of proving clinically that multiple sclerosis may exist in a benign form. Before attempting to draw conclusions from the present medium-length study the following facts must be borne in mind. The first relapse may be deferred for many years. Retrobulbar neuritis is usually quoted in this context, but the analysis of initial symptoms given earlier in the 14 patients who have not so far relapsed suggests that other types of onset may also be followed by a prolonged latent phase.

Published data on the frequency with which an acute retrobulbar neuritis, unaccompanied by other neurological signs, is later followed by evidence of multiple sclerosis are scarce and show variations in diagnostic criteria as well as in length of follow-up. Two examples will suffice. In 48 (50\%) of 97 cases of retrobulbar neuritis reported from Belfast by Beatrice Lynn (1959) signs of multiple sclerosis developed after a followup period ranging from 4 months to 29 years. With her co-operation those cases which had been under observation for less than five years were eliminated, leaving 67. During a mean follow-up period of 18 years $57(85 \%)$ showed other signs of the disease (McAlpine, Lumsden, Acheson, 1965). In striking contrast are the results of a recent study by Kurland, 
Auth, Beebe, Kurtzke, Lessell, Nagler, and Nefzger (1963) in 183 cases of acute retrobulbar neuritis derived from U.S. Army records (1942-8) and followed up 12 to 18 years later. Out of 45 men in whom "there were signs and symptoms sufficient to warrant a detailed neurologic review " only 24 were classified as cases of multiple sclerosis, a finding that signifies a rigid attitude towards this diagnosis.

It can be concluded that signs of multiple sclerosis will eventually appear in the majority of cases of uncomplicated acute retrobulbar neuritis provided the period of follow-up is long enough-that is, over 15 years. A similar statement could therefore apply to other forms of onset.

Attention has already been drawn to the fact that although the patient may not be conscious of any change in clinical status periodic examination may show signs indicating a reactivation of an old lesion or the appearance of a new one. In the absence of clinical relapse, therefore, it must not be assumed that the disease has "burnt out" (a phrase used by Mackay and Myrianthopoulos in 1958).

What are the prospects for the 62 patients in the present series who remain without disability after a mean duration of 18 years ? Bearing on this question are two observations. (1) Of the 78 patients in category unrestricted in $1959,12(15 \%)$ had become disabled by the spring of 1964. (2) A comparison of pyramidal and cerebellar signs with those found in earlier years in these 62 patients, along with an assessment of relapse rate, suggests that a further 12 patients may become disabled within the next five years. On this rough basis it can be estimated that by 1969 (20 years or more after the onset), 50 of the original 241 patients may remain without disablement due to the disease, although old age may lead to deterioration in some others.

With regard to the possible effect of treatment a single fact emerges from our 1961 analysis. Of the 78 patients in whom the disease subsequently ran a benign course, $50 \%$ were admitted to hospital within the first year of the disease, contrasting with the admission figures of $26 \%$ and $24 \%$, respectively, for those who subsequently died (83) or became disabled (80). "The period of rest in the early active stage of the disease, the advice given as to future mode of living, and the stress laid on rest in bed during a relapse may have played a part in modifying the course of the disease."

In view of the beneficial effect of A.C.T.H. on acute episodes of multiple sclerosis (Miller, Newell, and Ridley, 1961; Alexander and Cass, 1963) and the possibility that this or some related steroid agent may lessen the risk of relapse, the outlook for multiple sclerosis patients, especially those with good natural " resistance," should improve.

\section{Summary}

In 1959 the results of a follow-up of 241 cases of multiple sclerosis seen within three years of onset and observed for 10 years or more showed that $78(32 \%)$ were not disabled and were at work.
In the spring of 196463 of the 78 patients were re-examined; information about the remainder was obtained by letter. Results: dead, 3 (from an unrelated cause); disabled 12 ; unrestricted, 62 ; untraced 1.

The mean duration of the disease was 18.2 years. Thirtynine patients were aged 50 or over.

Presenting symptoms were paraesthesiae in $50 \%$, acute retrobulbar neuritis in $36 \%$, and motor weakness in $34 \%$.

A comparison of pyramidal and cerebellar signs observed within three years of onset and after 15 years confirms their importance in determining whether or not the disease will run a benign course. Early bilateral extensor plantar responses with little or no impairment of motor power were, however, present in 15 out of 62 patients still without disablement.

Pallor of one or both optic disks was present in $73 \%$, nystagmus in $31 \%$, and euphoria in $16 \%$ of the 63 patients examined in 1964.

So far 14 of the 74 patients have not relapsed. In some of these patients, however, old or fresh signs have been observed during the follow-up period.

An assessment of signs and relapse rate in the 62 patients at present without disablement suggests that roughly 50 of them-that is, $20 \%$ of the original 241 -may still be in category unrestricted in 1969, after a mean duration exceeding 20 years.

A comparison of admission rates in the first year of the disease in the original series of 241 patients who subsequently died, became disabled, or were unrestricted in 1959 suggests that early hospital care may be a factor in modifying the course of the disease, as may the introduction of A.C.T.H. as a therapeutic agent.

Without the generous help of patients and general practitioners this follow-up study could not have been completed. I also wish to thank Professor A. Kekwick and the members of the Clinical Research Committee of the Middlesex Hospital for facilities provided at the Institute of Clinical Research.

\section{REFERENCES}

Alexander, L., and Cass, L. J. (1963). Ann. intern. Med., 58, 454. Birley, J. L., and Dudgeon, L. S. (1921). Brain, 44, 150.

Brain, W. R. (1936). Lancet, 2, 866.

Bramwell, B. (1917). Edinb. med. 7., 18, 16.

Charcot, J. M. (1872). Leçons sur les maladies du système nerveux. Delahaye, Paris.

Ivers, R. R., and Goldstein, N. P. (1963). Proc. Mayo Clin., 38, 457.

Kurland, L. T., Auth, T. L., Beebe, G. W., Kurtzke, J. F., Lessell, S., Nagler, B., and Nefzger, M. D. (1963). Trans. Amer. neurol. Ass., 88, 231.

Lynn, B. H. (1959). Trans. Ophthal. Soc. U.K., 79, 701.

McAlpine, D. (1961). Brain, 84, 186.

- and Compston, N. (1952). Quart. f. Med., 21, 135.

Lumsden, C. E., and Acheson, E. D. (1965). "Multiple Sclerosis : A Reappraisal." "In press.

Mackay, R. P., and Myrianthopoulos, N. C. (1958). Arch. Neurol. - Psychrat. (Ćhic.), 80, 667.

Marie, P (1895). Lectures on Diseases of the Spinal Cord. New Sydenham Sociery, London.

Miller, H., Newell, D. J., and Ridley, A. (1961). Lancet, 2, 1120. 